\title{
Advances in Numerical Simulations of Hydrothermal Ore Forming Processes
}

\author{
Alexander Gysi $\mathbb{D}^{1},{ }^{1}$ Yuan Mei $\mathbb{D}^{2},{ }^{2}$ and Thomas Driesner ${ }^{3}$ \\ ${ }^{1}$ Colorado School of Mines, Golden, CO 80401, USA \\ ${ }^{2}$ CSIRO Mineral Resources, Australian Resources and Research Centre, Kensington, WA 6151, Australia \\ ${ }^{3}$ ETH Zurich, 8092 Zürich, Switzerland
}

Correspondence should be addressed to Alexander Gysi; agysi@mines.edu

Received 29 July 2019; Accepted 29 January 2020; Published 3 March 2020

Copyright $\odot 2020$ Alexander Gysi et al. This is an open access article distributed under the Creative Commons Attribution License, which permits unrestricted use, distribution, and reproduction in any medium, provided the original work is properly cited.

\section{Introduction}

Recent advances in numerical modeling techniques have led to unprecedented opportunities for exploring and quantifying the controlling factors of hydrothermal ore-forming processes. Such systems are challenging to study because the driving forces are mutually coupled and consist of complex chemical and physical processes of fluid-rock interaction that evolve transiently in space and time. Reading the geological and geochemical records archived in an ore deposit requires an in-depth understanding of both driving forces. Chemical reactions are responsible for hydrothermal alteration and metal mobilization from the source rocks and the spatially focused ore precipitation to eventually form a deposit. Understanding these chemical reactions requires modeling both the thermodynamics of complex fluid-mineral equilibria and the molecular controls of metal speciation in aqueous fluids. Physical processes drive fluid flow and the evolution of permeability, porosity, and fracture networks and thereby control the magnitude and efficiency of metal transport from source to deposition.

The increasingly rigorous and predictive capabilities of modern numerical methods allow developing quantitative scenarios to interpret field-based observations. Mutual refinement of simulations and data collection from the field makes a very powerful but still emerging tool in geosciences that permits constraining hydrothermal ore-forming processes. The purpose of this special issue is to bring together a series of contributions of research and review articles showing recent advances in the development and application of state-of-the-art numerical models for the simulation of oreforming processes. This issue covers aspects of molecular models of metal speciation, thermodynamics of fluid-rock equilibria, and large-scale physical and chemical reactive mass transport models.

\section{Topics Covered}

2.1. Thermodynamics of Fluid-Rock Equilibria. Geochemical modeling and the underlying thermodynamics of fluid-rock equilibria are essential tools for gaining a fundamental understanding of ore-forming processes in the crust. Geological fluids that transport metals can have a wide range of properties, origins, and evolution paths [1]. Magma bodies provide the heat, metals, and fluid sources necessary to form porphyry $\mathrm{Cu}-\mathrm{Mo}$ deposit and evolve to epithermal base and precious metal deposits at more shallow depths. These ore deposits can form through a complex array of geological processes including cooling and boiling/condensation of magmatic fluids, interaction with country rocks, and/or interaction with meteoric waters. Other deposits such as Mississippi Valley Type $\mathrm{Pb}-\mathrm{Zn}$ deposits and stratiform sediment-hosted $\mathrm{Cu}$ deposits commonly involve structural controls and the interaction of sedimentary formation waters with redox boundaries (e.g., [2]).

The thermodynamics of fluid-rock equilibria deals with various aspects of these chemically complex systems. The 
simulation of fluid-rock reaction paths predicts the chemistry of the fluids and the stable mineral assemblages between evolving equilibrium states. To calculate accurately the stabilities of these minerals, aqueous species, and gases requires the development of adequate activity models, equations of state, and underlying robust thermodynamic databases to correct for pressure, temperature, and nonideality of solutions (e.g., [3]). Solving these problems will enable us to constrain our understanding of metal solubility in hydrothermal fluids as a function of $\mathrm{pH}$, salinity, and the activities of ligands that complex with metals and control their mobility in geologic environments. This knowledge is the basic framework for simulating ore-forming processes and fluid-rock interaction at various scales and conditions and can be linked to the themes discussed in Sections 2.2 and 2.3.

2.2. Molecular Models of Metal Speciation. Metals are transported within the deep Earth at high pressure and temperature by fluids possessing a complex chemical makeup. The hydration and complexation of metals in hydrothermal fluids are key processes controlling the mobility of elements in the Earth's crust, leading to the formation of ore deposits from which the world's supply of $\mathrm{Fe}, \mathrm{Mn}, \mathrm{Ag}, \mathrm{Au}, \mathrm{Pd}, \mathrm{Cu}, \mathrm{Zn}, \mathrm{Co}, \mathrm{Pb}, \mathrm{U}$, and $\mathrm{Mo}$ is mined [4]. In the past 20 years, a large amount of in situ spectroscopic data, complemented by increasingly accurate $\mathrm{ab}$ initio molecular dynamics simulations and geochemical modeling, have dramatically improved our understanding of the chemical processes of metal transport in the upper crust [5].

$A b$ initio molecular dynamics (MD) simulations, whereby interatomic interactions are described by quantum mechanics, provide a means to determine the nature and stabilities of metal complexes under conditions that are beyond experimental practicality (as reviewed in [6]). This approach is made possible by the availability of high-performance computing resources and the implementation of density functional theory [7]. The metal speciation and hydration properties at a wide range of temperature and pressure could be accurately predicted by using ab initio molecular dynamics. The advances of computational approaches of enhanced sampling allow us to calculate the free energy of chemical reactions from constrained molecular dynamics [8]. Therefore, we can use this method to derivate the thermodynamic properties of metal complexation reactions. Molecular dynamics simulation also provides a new approach to investigate the structural and thermodynamic properties of minerals and melts; thus, now we are able to predict the trace element partitioning between minerals and melts. Combined with advanced experimental approaches such as synchrotronbased in situ X-ray absorption spectroscopy and in situ Raman spectroscopy, the molecular simulations provide an independent cross-check of the speciation and thermodynamics of metal and ligands in ore-forming fluids. These approaches give molecular-level insights into the chemical processes responsible for the formation of ore deposits (as reviewed in [5]).
2.3. Large-Scale Physical and Chemical Reactive Mass Transport Models. Hydrothermal ore deposits form in fluidflow systems that are much larger than the deposit itself. Understanding the ore-forming process, therefore, requires thinking in a "mineral systems" framework comprising the metal, fluid, and ligand sources, the driving forces, the flow paths, and the ore deposition site. Numerical simulation of fluid flow can provide valuable inputs to establish that framework and to distinguish between scenarios that honor the physics of the flow process of heat and mass transfer and other scenarios that may seem intuitive from a field perspective but are physically unrealistic. A key value of physically plausible models is that they make predictions that can often be tested in the field to improve our conceptual understanding of how these natural systems work.

The prime example of such system-scale modeling is that of fluid flow around a cooling pluton, for which robust understanding emerged when the full properties of water, correct treatment of boiling, and temperature-dependent permeability models were introduced by Hayba and Ingebritsen [9]. Later, more complex saltwater properties in magmatic fluids have refined our view of epithermal and magmatic-hydrothermal ore-forming processes and made predictions such as the role of magmatic vs. meteoric fluids testable [10]. Future directions will incorporate the mutual feedback between fluid flow, heat transfer, mineral dissolution/precipitation, and rock mechanics, namely, represented explicitly by fracture mechanics. The latter is key to understanding the transient nature of permeability in ore-forming systems and to determining the causes of structural controls of ore deposition. These advances will permit exploring questions such as do fractures control the path of ore-forming fluids or does fluid pressure activate those fractures that are in particularly favorable places for dissipating fluid pressure?

Besides epithermal and magmatic-hydrothermal deposits, simulation studies have focused on basin-hosted ore-forming systems and on submarine massive sulfide deposits along active spreading ridges and submarine arc volcanoes. Future studies on basin-hosted deposits will likely test a broader spectrum of scenarios including the actual basin evolution with evaporation and tectonic events. The bottleneck in advancing frontiers in simulating submarine massive sulfide formation arguably is the lack of thermodynamic models for solutes in such fluids at supercritical conditions, which prevents the application of reactive transport models. The computational chemistry methods mentioned in Section 2.2 will likely play a key role in closing this gap.

\section{Highlights and Contents of the Special Issue}

3.1. "CuCl Complexation in the Vapor Phase: Insights from $\mathrm{Ab}$ Initio Molecular Dynamics Simulations" by Y. Mei et al. In this study, the authors used ab initio molecular dynamics simulation to investigate the hydration of the $\mathrm{CuCl}^{0} \mathrm{com}$ plex in $\mathrm{HCl}$-bearing water vapor at fluid density of 0.02 $0.09 \mathrm{~g} / \mathrm{cm}^{3}$ at a molecular level. The simulation results indicate the $\mathrm{CuCl}^{0}$ complex is stabilized by the second- 
shell hydration and H-bonds in low-density fluids. The highlight of this research is the first theoretical confirmation that beyond-first-shell-hydrated metal complexes play an important role in metal transport in low-density hydrothermal fluids.

3.2. "Thermodynamic Properties of Aqueous Species Calculated Using the HKF Model: How Do Different Thermodynamic and Electrostatic Models for Solvent Water Affect Calculated Aqueous Properties?" by G. D. Miron et al. The fundament of modeling chemical fluid-rock interaction is thermodynamic formalisms that describe the properties of solutes as a function of temperature, pressure, and fluid composition. These formalisms, in turn, are based on conceptual physical models of molecular interactions (water-water, water-solute, and solute-solute) in the fluids that require accurate representations of water properties such as density and static dielectric constant. While these are available at high accuracy for ambient conditions, uncertainties about the correct representation increase with increasing temperature and pressure. G. D. Miron et al. provide an assessment of the sensitivity of the widely used HKF model to different published representations of water volumetric and dielectric properties. Their findings highlight that current limitations of thermodynamic modeling of high-temperature ore-forming processes are not a problem of modeling software but of the underlying experimental data and thermodynamic models that need to be improved.

3.3. "Rare Earth Elements in Mineral Deposits: Speciation in Hydrothermal Fluids and Partitioning in Calcite" by E. P. Perry and A. P. Gysi. In this study, the authors simulate the speciation and solubility of REE in hydrothermal fluids associated to carbonatites and relevant to REE mineral deposits. A series of speciation diagrams were produced, explaining the stable REE complexes in equilibrium with a calcite vein as a function of $\mathrm{pH}$. The highlight of this research is the simulation of progressive variations and incorporation of REE into hydrothermal calcite as a function of temperature, salinity, and ligand activities of the hydrothermal fluids. The study highlights that the varying LREE vs. HREE compositions of calcite can be used to interpret conditions of formation in ore deposits.

3.4. "Uranium Transport in F-Cl-Bearing Fluids and Hydrothermal Upgrading of U-Cu Ores in IOCG Deposits" by $Y$. Xing et al. In this study, the authors review the thermodynamic properties of U(IV/VI)-F, U(IV/VI)-Cl, and $\mathrm{U}(\mathrm{IV} / \mathrm{VI})-\mathrm{OH}$ aqueous complexes under hydrothermal conditions. Based on this, the relative importance of $\mathrm{F}$ and $\mathrm{Cl}$ in hydrothermal transport of $\mathrm{U}$ was compared by calculating the solubility of uraninite and $\mathrm{U}_{3} \mathrm{O}_{8}(\mathrm{~s})$ in acidic F-bearing solutions $(\mathrm{Cl}: \mathrm{F}=100)$ at $25-450^{\circ} \mathrm{C}$. Furthermore, reactive transport modeling was performed to simulate the alteration of low-Cu- $\mathrm{U}$ magnetite-dominated ores by hematite-stable fluids. The study shows that fluoride is important for $\mathrm{U}$ transport mainly at $T<250^{\circ} \mathrm{C}$, whereas above $250^{\circ} \mathrm{C}$, chloride is more important. Fluorine plays a less important role in controlling $\mathrm{U}$ endowment in IOCG deposits, and the coenrichment of $\mathrm{F}$ and $\mathrm{U}$ in the ore can be achieved via late-stage alteration and upgrading processes.

3.5. "Fluid Chemistry of Mid-Ocean Ridge Hydrothermal Vents: A Comparison between Numerical Modeling and Vent Geochemical Data" by S. Pierre et al. Numerical modeling was used to explore the evolution of mineralogy and fluid chemistry in the seawater-basalt system up to $400^{\circ} \mathrm{C}$ at 500 bar. These simulations were used to determine the proton and cation activities, $\mathrm{pH}$, and redox evolution of seawater at various equilibration stages and fluid-rock ratios. The highlight of this manuscript is the comparison of simulated fluid chemistry with geochemical data measured in submarine hydrothermal vent fluid compositions from mid-ocean ridges. These comparisons permit interpreting the natural data as a function of temperature and fluid-rock ratios.

3.6. "Permeability Changes Resulting from Quartz Precipitation and Dissolution around Upper Crustal Intrusions" by S. W. Scott and T. Driesner. Strong pressure and temperature gradients experienced by fluids circulating around cooling magmatic intrusions may induce significant porosity and permeability changes due to mineral dissolution and precipitation. S. W. Scott and T. Driesner present generic simulations of quartz dissolution/precipitation that allow a first-order quantification of the problem. Due to the retrograde solubility of quartz above ca. $350^{\circ} \mathrm{C}$, groundwater recharging the hydrothermal system will first dissolve silica on the heating path towards the intrusion but then reprecipitate it near the intrusion as it gets heated further. However, as the precipitation zone changes transiently with the inward cooling of the intrusion, the overall clogging effect appears to be limited and remains moderate for host rocks with a primary porosity $>0.05$. These findings may be relevant for the future exploitation of superheated geothermal systems as currently explored in Iceland.

3.7. "Modelling Seismically Induced Mesothermal Goldfields along the Deep-Rooted Cadillac-Larder Lake Fault, Abitibi, Canada" by P. Bedeaux et al. This study investigates the regional-scale interplay between seismicity, fault activation, and crustal permeability and their structural controls on gold deposition. Static stress modeling was used to quantify and explore the role of the Cadillac-Larder Lake Fault and Archean seismicity in the development of hydrothermal systems and the genesis of the regional goldfields in Abitibi, Canada. Repeated occurrences of seismically triggered hydrothermal fluid flow along long-existing focused fluid pathways led to iterative ore formation into supracrustal discharge zones by means of episodic drops and build-ups of pressure. The highlight of this manuscript was to show that these modeled zones correlate positively with the actual observed gold distribution in Abitibi, such as the Rouyn and Malartic goldfields associated to seismic ruptures along the Joannes Segment. These simulated damage zones were also shown to correlate with the regional metasomatic footprint and may be used as an exploration tool. 


\title{
Conflicts of Interest
}

The editors declare that they have no conflicts of interest regarding the publication of this special issue.

\author{
Alexander Gysi \\ Yuan Mei \\ Thomas Driesner
}

\section{References}

[1] B. W. D. Yardley, "100th anniversary special paper: metal concentrations in crustal fluids and their relationship to ore formation," Economic Geology, vol. 100, no. 4, pp. 613-632, 2005.

[2] N. C. Hurtig, J. J. Hanley, and A. P. Gysi, "The role of hydrocarbons in ore formation at the Pillara Mississippi Valleytype $\mathrm{Zn}-\mathrm{Pb}$ deposit, Canning Basin, Western Australia," Ore Geology Reviews, vol. 102, pp. 875-893, 2018.

[3] G. D. Miron, T. Wagner, D. A. Kulik, and B. Lothenbach, "An internally consistent thermodynamic dataset for aqueous species in the system Ca-Mg-Na-K-Al-Si-O-H-C-Cl to $800^{\circ} \mathrm{C}$ and 5 kbar," American Journal of Science, vol. 317, no. 7, pp. 755806, 2017.

[4] T. M. Seward and H. L. Barnes, "Metal transport by hydrothermal ore fluids," in Geochemistry of Hydrothermal Ore Deposits, H. L. Barnes, Ed., pp. 435-486, Wiley, New York, 3rd edition, 1997.

[5] J. Brugger, W. Liu, B. Etschmann, Y. Mei, D. M. Sherman, and D. Testemale, "A review of the coordination chemistry of hydrothermal systems, or do coordination changes make ore deposits?," Chemical Geology, vol. 447, pp. 219-253, 2016.

[6] D. M. Sherman, "Quantum chemistry and classical simulations of metal complexes in aqueous solutions," Reviews in Mineralogy and Geochemistry, vol. 42, no. 1, pp. 273-317, 2001.

[7] R. Car and M. Parrinello, "Unified approach for molecular dynamics and density-functional theory," Physical Review Letters, vol. 55, no. 22, pp. 2471-2474, 1985.

[8] M. Sprik and G. Ciccotti, "Free energy from constrained molecular dynamics," The Journal of Chemical Physics, vol. 109, no. 18, pp. 7737-7744, 1998.

[9] D. O. Hayba and S. E. Ingebritsen, "Multiphase groundwater flow near cooling plutons," Journal of Geophysical Research, vol. 102, no. B6, pp. 12235-12252, 1997.

[10] S. Fekete, P. Weis, T. Driesner, A. S. Bouvier, L. Baumgartner, and C. A. Heinrich, "Contrasting hydrological processes of meteoric water incursion during magmatic-hydrothermal ore deposition: an oxygen isotope study by ion microprobe," Earth and Planetary Science Letters, vol. 451, pp. 263-271, 2016. 